\title{
Neurology, psychiatry and the chess game: a narrative review
}

\author{
Neurologia, psiquiatria e o jogo de xadrez: uma revisão narrativa \\ Gustavo Leite FRANKLIN', Brunna N. G. V. PEREIRA², Nayra S.C. LIMA³, Francisco Manoel Branco GERMINIANI', \\ Carlos Henrique Ferreira CAMARGO4, Paulo CARAMELLI5 , Hélio Afonso Ghizoni TEIVE ${ }^{1,4}$
}

\begin{abstract}
The chess game comprises different domains of cognitive function, demands great concentration and attention and is present in many cultures as an instrument of literacy, learning and entertainment. Over the years, many effects of the game on the brain have been studied. Seen that, we reviewed the current literature to analyze the influence of chess on cognitive performance, decision-making process, linking to historical neurological and psychiatric disorders as we describe different diseases related to renowned chess players throughout history, discussing the influences of chess on the brain and behavior.
\end{abstract}

Keywords: cognition; recreational games; neurology; psychiatry; decision making; behavior; history.

\section{RESUMO}

O jogo de xadrez compreende diferentes domínios da função cognitiva, exige grande concentração e atenção e está presente em muitas culturas como instrumento de alfabetização, aprendizado e entretenimento. Ao longo dos anos, muitos efeitos do jogo no cérebro foram estudados. Dessa forma, revisamos a literatura atual para analisar a influência do xadrez no desempenho cognitivo, no processo de tomada de decisão, vinculando-a a distúrbios neurológicos e psiquiátricos históricos ao descrevermos diferentes doenças relacionadas a renomados jogadores de xadrez ao longo da história, discutindo as influências do xadrez no cérebro e no comportamento.

Palavras-chave: cognição; jogos recreativos; neurologia; psiquiatria; tomada de decisões; comportamento; história.

The chess game first description dates back to the $6^{\text {th }}$ century $\mathrm{AD}$ in India, and in the $10^{\text {th }}$ century it spread from Asia to Europe $^{1}$. Once a leisure game, chess reached the level of championships and competitions by the late $19^{\text {th }}$ century, leading to its popularity over the following decades. This game is played on a chessboard, a square board divided into 64 squares (eight-by-eight) of two alternating colors, which is similar to that used in draughts (checkers) (Figure 1)2.

Chess is considered a complex game, which requires cognitive training and expertise ${ }^{3-6}$. In the last 30 years, numerous studies evaluating brain activity in chess players have been

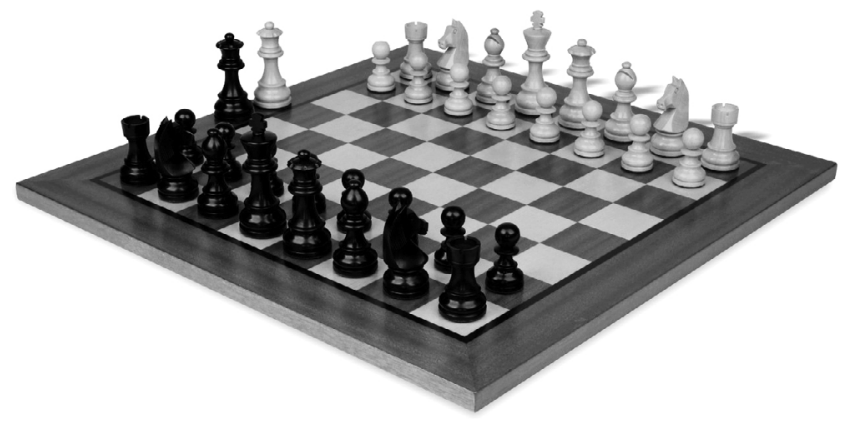

Source: Public Domain, no copyrights applied.

Figure 1. Chessboard.

\footnotetext{
'Universidade Federal do Paraná, Hospital de Clínicas, Departamento de Medicina Interna, Serviço de Neurologia, Curitiba PR, Brazil. ${ }^{2}$ Hospital da Cruz Vermelha, Departamento de Neurologia, Curitiba PR, Brazil.

${ }^{3}$ Universidade de Vila Velha, Vila Velha ES, Brazil.

«Universidade Federal do Paraná, Hospital de Clínicas, Programa de Pós-Graduação em Medicina Interna, Grupo de Doenças Neurológicas, Curitiba PR, Brazil. ${ }^{5}$ Universidade de Minas Gerais, Hospital das Clínicas, Departamento de Medicina Interna, Grupo de Pesquisa de Neurologia Cognitiva e Comportamental, Belo Horizonte MG, Brazil.

Gustavo Leite FRANKLIN (iD https://orcid.org/0000-0002-0207-3671; Brunna N. G. V. PEREIRA iD https://orcid.org/0000-0003-0588-5226; Nayra S.C. LIMA (ID https://orcid.org/0000-0001-8243-2859; Francisco Manoel Branco GERMINIANI (iD) https://orcid.org/0000-0001-9494-9759; Carlos Henrique Ferreira CAMARGO (ID) https://orcid.org/0000-0002-3533-0347; Paulo CARAMELLI ID https://orcid.org/0000-0002-4786-6990; Hélio Afonso Ghizoni TEIVE (iD) https://orcid.org/0000-0003-2305-1073

Correspondence: Gustavo Leite Franklin; Rua General Carneiro, 181 - Centro; 80060-900 Curitiba PR, Brazil; E-mail: gustavolf_88@hotmail.com Conflict of interest: There is no conflict of interest to declare. Received on August 27, 2019; Received in its final form on October 21, 2019; Accepted on October 28, 2019.
} 
published ${ }^{7}$. Different studies using neuroimaging and neuropsychological tests evaluated individuals with chess expertise in an attempt to define which major areas of the brain are associated to game performance, reasoning about the brain activity associated to chess-relevant cognition and the neural substrate underlying problem-solving mechanisms ${ }^{1-14}$.

Chess players are usually stereotyped as intelligent or with unusual skills. Indeed, there are some studies that try to realign the degree of intelligence to the psychometric aspects of chess players ${ }^{15}$. Otherwise, players tend to be more introverted, intimate and intuitive than the non-player population, as showed by Kelly et al., who analyzed a sample of 270 average players and 209 masters and concluded that chess players had significantly higher scores on introversion, intuition and thinking when compared to the general population norms. Also, Avni et al. employed selected scales of the Minnesota Multiphasic Personality Inventory (MMPI) and found that chess players differ from non-players in terms of unconventional thinking and orderliness ${ }^{16,17}$.

Like other competitive games, players are often submitted to a lot of pressure and may be associated to worsening anxious and compulsive personalities. Perhaps for these reasons, teaching chess aiming cognitive improvement in primary school is still questioned ${ }^{4,13}$.

Although there are many studies related to the chess game, they tend to focus on limited aspects of the game or its practice. In this way, the aim of this review was to group different scientific perspectives related to memory, cognition and decision-making, and to analyze possible influences of the chess practice for brain and behavior, also providing a historical perspective of some neuropsychiatric disorders related to renowned chess players of all time.

\section{METHODS}

A literature review was performed on the results of the database searches from June to September 2018. The articles were selected from PubMed database and published chess books and biographies, to compose the historical note present in the paper. The paper was designed following three lines of research related to the chess game. First, the cognitive aspects related to the game, in which we include studies on decision-making, memory and neural circuits associated to the practice of playing chess. Second, the possible influences of playing chess on brain performance, behavior, and even on the body. In the third topic, we searched for historical aspects related to neurological and psychiatric diseases of iconic chess players.

To find representative articles, the following keywords were input, respectively, to elucidate each line of research: 1. [cognition AND chess]; [decision making AND chess]; [memory AND chess]; [memory AND cognition AND chess]; [cognition AND recreational games]; [memory AND recreational games]; [intelligence AND chess]; [brain AND chess]; [neurology AND chess]; 2. [behavior AND chess]; [educational AND chess]; [stress, psychological AND chess]; [psychology AND chess] [psychology AND behavior]; 3. [history AND chess]; [stroke AND chess]; [schizophrenia AND chess] [psychiatry AND chess]. The articles in this review were selected only when the full text or chapter was available in the database and were excluded from the sample if the text mentioned the exclusive study of a recreational game other than chess. Although the keywords searched were determined for each research section, some articles cited may be present in other parts of the paper to maintain the fluidity of the article.

\section{RESULTS}

In the initial screening, using the above-mentioned keywords, 58 articles and 21 published books were found. Out of these, 24 articles and 6 books were excluded because they were redundant, had repeated information, or were unrelated to the game or chess players, so we included 34 articles and 15 published books.

\section{DISCUSSION}

\section{Chess and cognitive function}

In general, the results of studies that evaluated the cognitive abilities of chess players vary widely. This is true for both neuropsychological and neuroimaging studies ${ }^{5-18}$. A pioneering study of chess players published by Binet, in 1966, identified a mnemonic virtuosity in these players 9 . However, other studies evaluating working memory ${ }^{12}$, visuospatial abilities ${ }^{14}$ and planning performance ${ }^{5}$ in chess players showed different or inconclusive results ${ }^{18}$. In 1998, Gobet et al. compared four theories of expertise in relation to chess players' memory and concluded that the "Template theory", a unified theory which associates the "Chunking theory" to schematic knowledge and planning process, helps to explain chess players' performance ${ }^{7}$. The Chunking theory described by Chase and Simon states that the ability of chess players to copy and recall positions are due to the expert's storage in long-term memory of many different patterned clusters of pieces (or chunks) ${ }^{19,20}$.

Lane and Chang studied a sample of 79 chess players and used different cognitive tests, including a memory test for chess positions, a test of declarative chess knowledge, a test of fluid intelligence and a questionnaire evaluating the amount of time spent playing and studying chess. They concluded that high-level conceptual processing in chess players plays an important role in memory ${ }^{21}$. Despite emphasizing memory, these results do not contradict the previous template theory by Gobet and Simon. This theory was once again sedimented in 2016, when in a comprehensive meta-analysis; Burgoyne et al. studied the relation between cognitive 
abilities and chess skills. They concluded that chess skills correlate positively with fluid reasoning, comprehension-knowledge, short-term memory, and processing speed, particularly in young chess players ${ }^{22}$. In 2017, Sala et al. conducted another meta-analysis, in which they compared the performance of chess players and non-chess players in intelligence-related skills. Their study also confirmed that chess players outperformed non-chess players in these skills, thus supporting the idea that intelligence plays an important role in the acquisition of expertise and contradicting the academic-selectionprocesses argument ${ }^{23}$.

Several studies, in which neuroimaging were used, including magnetic resonance imaging (MRI), functional magnetic resonance imaging ( fMRI), single photon emission computed tomography (SPECT) and positron emission tomography (PET) (Table 1), tried to define which areas of the brain are related to chess playing ${ }^{3-18}$.

Onofrj et al., in 1995, using SPECT to detect cerebral activation, studied five expert male chess players during the mental solution of a complex chess problem. They concluded that non-dominant dorsal-prefrontal activation during chess problem solution could be detected by SPECT ${ }^{10}$. Rennig et al. published a paper in 2013, in which they analyzed the results of four fMRI studies that compared chess experts and chess novices when complex visual stimuli were presented during a chess game. They found that the temporoparietal junction plays an important role in the processing of complex visual stimuli in chess experts ${ }^{24}$. Hänggi et al. published a study in 2014, investigating morphological differences in chess players' brains. They showed that mean diffusivity was increased in chess players compared to controls in the upper left longitudinal fasciculus and the expertise (evaluated by the Elo score - a chess tournament ranking) was inversely related to mean diffusivity within the right superior longitudinal fasciculus, highlighting that there are specific differences in grey and white matter morphology between chess players and non-players in brain regions associated to cognitive functions for playing

Table 1. Neuroimaging and the game of chess.

\begin{tabular}{|c|c|c|c|}
\hline Activated areas & $\begin{array}{l}\text { Associated } \\
\text { activity }\end{array}$ & Exam & References \\
\hline $\begin{array}{l}\text { Left superior } \\
\text { longitudinal } \\
\text { fasciculus }\end{array}$ & NA & MRI & 1 \\
\hline $\begin{array}{l}\text { Parietal areas and } \\
\text { the left frontal lobe }\end{array}$ & Spatial task & fMRI & 6 \\
\hline $\begin{array}{l}\text { Non dominant } \\
\text { prefrontal area } \\
\text { Non-dominant } \\
\text { middle temporal area }\end{array}$ & $\begin{array}{l}\text { Solution of } \\
\text { a complex } \\
\text { chess } \\
\text { problem }\end{array}$ & SPECT & 10 \\
\hline $\begin{array}{l}\text { Temporo-parietal } \\
\text { junction }\end{array}$ & $\begin{array}{l}\text { Processing } \\
\text { of complex } \\
\text { visual stimuli }\end{array}$ & fMRI & 24 \\
\hline
\end{tabular}

chess. Their findings are not enough to conclude whether they are the cause or consequence of the intensive and longterm chess training and practice, but complement the investigation on brain activity associated to chess-relevant cognition and may help elucidate the neural substrate underlying problem-solving and decision-making mechanisms ${ }^{3}$.

Decision-making is regarded as the cognitive process resulting from the selection of a belief or a course of action among several alternative possibilities. Every decision-making process produces a final choice, which may or may not prompt action. Such tasks engage decision-making processes, that determine which movement to make next and when to make it, how those movements that are selected are planned and controlled, and how movements and task goals are dynamically updated in response to changes in the world. In decision making, the decision variable is the accumulated evidence in favor of one decision over another ${ }^{11}$.

The role of the amygdala in the decision-making process was reviewed by Bechara et al. in 2003. They presented strong evidence in support of the hypothesis that the amygdala and the orbitofrontal cortex are part of a neural circuit involved in decision making. The authors defined primary inducers as "stimuli that unconditionally, or through learning, can produce states that are pleasurable or aversive", and secondary inducers as "entities generated by the recall of an emotional event, that generates thoughts and memories about the inducer, eliciting a somatic state". They concluded that the amygdala is a critical substrate in the neural system and is needed to link the orbitofrontal cortex, trigger somatic states from primary inducers and, additionally, stated that the ventromedial cortex plays a critical role in the neural system, necessary for the triggering of somatic states from secondary inducers ${ }^{25}$.

More recently, Gläscher et al., studying 344 individuals with focal brain lesions, 165 of whom had lesions in the prefrontal cortex (PFC), confirmed that there is a remarkable functional-anatomical correlation between the PFC and value-based decision making ${ }^{26}$. Liebherr et al. published an interesting study demonstrating the importance of considering decision making in older adults in 2017. They pointed out the relevance of learning and of cognitive and emotional contributors responsible for age-related differences in decision making ${ }^{27}$. Recently, several studies have confirmed that decision making is also linked to emotional intelligence, contradicting a previous hypothesis, that stated it was a purely rational and cognitive process ${ }^{28}$.

In chess, "Kotov's Syndrome" was first described by the Russian chess grandmaster and author Alexander Alexandrovich Kotov (Figure 2A), in his book "Think like a Grand Master"29. The syndrome refers to the situation in which a chess player, after studying a complicated position in great depth for a long time and failing to find a suitable variant, notices that he/she is running out of time and quickly makes a move that he/she has not yet analyzed and is often 
incorrect, thereafter losing the game ${ }^{29}$. This situation clearly involves decision making and emotional intelligence. In 2017, Alipour et al. published a case report on the use of quantitative electroencephalography in an eight-year-old boy with substantial chess training while he was playing chess against a computer. The authors observed a lower power spectral density in higher frequency bands in the right hemisphere in decision making during the game ${ }^{30}$.

\section{Influences of chess on brain and behavior}

In a Spanish study conducted in eight schools, children who played chess as an extracurricular activity were compared to children who chose other activities, such as soccer and basketball ${ }^{31}$. Children were assessed at the beginning and end of the school year with the WISC-R intelligence test, a selfassessment test (TAMAI) and an evaluation by their teachers. The results showed chess to be a great educational tool. They concluded that after one year of practicing, children performed better on tests that measured attention, organization, speed, planning, and problem-solving ${ }^{31}$. In a previous study, Atherton et al. investigated whether the predominant cognitive domain involved in the board game was logic or spatial ability. They conducted an MRI study and found a pattern of cerebral activation involving parietal areas and the left frontal lobe, suggesting that spatial ability is predominant. Much of this activation is probably due to thinking about possible moves and anticipating the opponent's next move ${ }^{6}$.

Chess has also been studied as a tool for treating schizophrenic patients. In one study, 26 clinically stable patients who were on antipsychotics and had normal IQs were divided into two groups: a chess group, whose members were given training and played chess, and a control group ${ }^{32}$. All the subjects were assessed with a battery of cognitive tests. After 10 hours of training in chess skills, the chess group had a better planning score, indicating that playing chess may be a valuable tool in the treatment of these patients ${ }^{33}$.

More recently, it has been suggested that being taught chess improves elementary school students' mathematical skills $\mathrm{s}^{34}$, but this remains a controversial issue ${ }^{35}$. Sala et al. studied the effects of chess instruction on the students' cognitive and academic skills in 2017, and concluded that exposure to chess instruction is associated to better mathematics performance in the general population of elementary school students in the short-term. However, this finding was not confirmed after additional experimental studies with an active control group ${ }^{22-24}$.

The discussion about stress in chess players was studied by Troubat et al., in 2009, who evaluated the effects of psychological stimuli on physiological responses. They studied the effects of playing chess in chess competitors with a series of cardiorespiratory and metabolic variables. It was observed that since the beginning of the contest, heart rate was rather elevated and both heart rate and respiratory exchange ratio slightly increased during the game. Such elevated levels could indicate that substrate oxidation mainly involved carbohydrates. The authors concluded that high cognitive demands during a chess game resulted in sympathetic activation, with great heart rate variability and increased arterial blood pressure ${ }^{36}$.

\section{Historical neurological and \\ psychiatric aspects related to chess players}

Many chess players have become renowned for their brilliance and feats on the board, only losing to themselves in their own brilliance. Many grandmasters have been afflicted by neuropsychiatric disorders (Table 2), which blighted their careers and prematurely ended their lives ${ }^{37-41}$.

The very first world champion, Wilhelm Steinitz, was no exception. Short, bald and with a congenital "lameness" disease, Steinitz was not physically impressive ${ }^{37}$. At the chessboard, however, he used to become a majestic figure. In 1862, he won the London championship and in 1866 he played against Adolf Anderssen, considered the world's best player at the time. Although he declared himself the world champion after beating Anderssen, it was only after winning the first official World Championship, held in the USA in 1886, that Steinitz was formally named the first Chess Champion of the World, a title he was to retain until 1894. In June 1899, however, his mental health began to deteriorate rapidly. He claimed
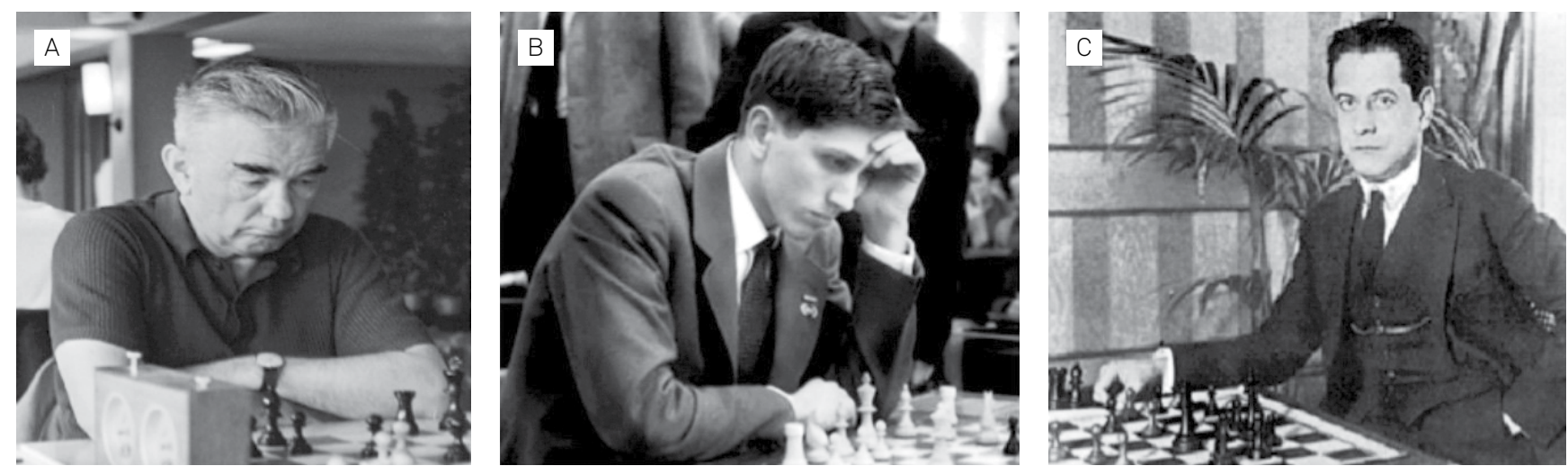

Figure 2. (A) Alexander Alexandrowitsch Kotov (1913-1981); (B) Robert James "Bobby" Fischer (1943-2008); (C) José Raul Capablanca (1888-1942). 
that he could talk to any person anywhere by telepathy and move chess pieces with a mere thought. He would spend each morning walking barefoot in the small yard behind his New York home, regardless of the weather, and try to call people with his "wireless phone". As the years went by, he veered into a much more serious state of psychosis. For some time, he was confined to a Moscow Asylum. He insisted that he had played chess with God and "God lost" 37 . He was hospitalized in the East River Sanatorium on Wards Island in Manhattan, where he died of a heart attack on August $12^{\text {th }}, 1900^{37-42}$.

One of the most remarkable psychiatric cases in chess history was that of Robert James Fischer (Figure 2B). In 1957, his daring and innovative gaming made "Bobby Fischer", at 14 years old, the youngest winner ever of the U.S. Chess Championship. According to Frank Brady, author of one of the most famous biographies of Fischer, Bobby Fischer seemed to be very eccentric and lack conventional social skills since his childhood. During his early adolescence, Fischer consulted with, at least, three different mental health professionals. After beating Boris Spassky and winning the World Chess Championship in 1972, Bobby lapsed into a period of growing paranoia and isolation, manifested primarily as an aggressive anti-Semitism and pathological fearfulness ${ }^{43}$. Although one diagnosis suggested that he suffered from Asperger's syndrome, which is supported by his significantly impaired ability to relate to others, stereotyped and repetitive behaviors and by an exaggerated focus on one area of interest since early childhood. Fischer did not meet all the necessary criteria for a differential diagnosis between Asperger's syndrome and schizoid personality disorder ${ }^{44}$. There is also evidence of paranoid personality disorder because of his long-standing pattern of pervasive distrust and suspiciousness of others and his interpretation of other people's behavior as malevolent.

Table 2. Psychiatric and neurological diseases in chess players.

\begin{tabular}{|c|c|c|}
\hline Chess player & Disease & References \\
\hline Wilhelm Steinitz & Psychosis/Schizophrenia & 37,38 \\
\hline $\begin{array}{l}\text { Robert James } \\
\text { Fisher }\end{array}$ & $\begin{array}{c}\text { Asperger's syndrome/ } \\
\text { Schizoid personality } \\
\text { disorder }\end{array}$ & 38,43 \\
\hline $\begin{array}{l}\text { Paul Charles } \\
\text { Morphy }\end{array}$ & Psychosis-Schizophrenia & 33,38 \\
\hline Lembit Oll & $\begin{array}{c}\text { Depression/Bipolar } \\
\text { disorder }\end{array}$ & 38,39 \\
\hline Karen Grigorian & Depression/Suicide & 38,40 \\
\hline George Mackenzie & Depression/Suicide & 38 \\
\hline Alvis Vitolins & Depression/Suicide & 38,41 \\
\hline $\begin{array}{l}\text { José Raul } \\
\text { Capablanca }\end{array}$ & Hemorrhagic Stroke & $45,46,48$ \\
\hline Harry Pillsbury & Neurosyphilis/Stroke & 48,49 \\
\hline
\end{tabular}

Furthermore, Fischer had an unstable family life, experienced the pressure of early fame and may have had a genetic predisposition toward psychological difficulties. He died of kidney failure on January $17^{\text {th }}, 2008$, in Reykjavík, Iceland, where he had played against Spassky three decades before to become the first American-born world chess champion ${ }^{43}$.

Paul Charles Morphy, the New Orleans chess prodigy, who was active in chess a century before Bobby, also lapsed into a state of delusion and paranoia, in his case, centered on a belief that he was being persecuted by his brother-in-law. In many letters, his best friend, Charles Maurian, noted that Morphy was "deranged" and "not right mentally". In 1882, his mother, brother and a friend tried to admit him to a Catholic sanitarium called Louisiana Retreat, but he was so well able to argue for his rights and sanity that they sent him away. Two years later, Morphy was found dead in his bathtub at the age of 47. The autopsy showed that he had died of a stroke ${ }^{33-38}$.

Like Morphy, many grandmasters were afflicted by strokes and other neurological disorders. An iconic case was Capablanca. José Raúl Capablanca was born in Havana, Cuba, in 1888 (Figure 2C). According to his own accounts, he learned the rules of the game at the age of four by watching his father playing. He won the Cuban Chess Championship when he was 12 and the World Chess Championship against the German Emmanuel Lasker in Havana in 1921. He was a contemporary of the greatest chess players of all time, such as Akiba Rubistein, Alexander Alekhine, Frank Marshall and Siegbert Tarrash $^{37-46}$. Capablanca was described as very anxious, particularly during chess games and, in 1921, Capablanca began to complain of "sanguineous uneasiness" ${ }^{45,46}$. In fact, uncontrolled hypertension caused him frequent, severe headaches, and as a result, he had difficulty competing in championships. On the evening of March $7^{\text {th }}$, while watching a game at the Manhattan Chess Club, Capablanca suffered a severe headache and, suddenly, lost consciousness. He was quickly taken to the hospital but died six hours after being admitted ${ }^{45}$. A full autopsy showed complete destruction of the right thalamus and the adjacent portion of the corpus striatum, replaced by a large intraparenchymal hematoma. The ventricular system was completely filled with blood, dilated throughout and displaced somewhat to the left ${ }^{47}$.

Harry Pillsbury, another world-class chess player, known for his memory skills and blindfolded playing, also had a neurological disease, which culminated in his death. According to many reports, at the beginning of the $20^{\text {th }}$ century, he used to have frequent headaches and had three different strokes, leaving him partly paralyzed ${ }^{48}$. The etiology of the strokes is uncertain, but in March 1905 Pillsbury was hospitalized for complications of neurosyphilis. Harry's health condition was so severe that in a psychotic outbreak he tried to jump out of a four-store window at the hospital. He died at the age of 33 at Friends Asylum in Frankford, Pennsylvania. His obituary in the New York Times stated that he died from an "illness contracted through overexertion of his memory cells" 49 . 


\section{CONCLUSION}

Chess is an intellectually complex, strategically demanding and highly competitive game. Although further studies might be needed to provide greater evidence of the real effects of the game on the cognition process, there are many benefits described in the literature. There are also several studies highlighting possible influences of the practice of chess on brain, body and behavior, which give us an insight on the broad spectrum of actions of the practice of playing chess and its possible use as a learning and therapeutic tool.

\section{References}

1. Murray HJR. A History of Chess. Oxford: Clarendon Press; 1913.

2. International Chess Federation. FIDE laws of chess. Lausanne, Switzerland: FIDE; 2008.

3. Hänggi J, Brütsch K, Siegel AM, Jänke L. The architecture of the chess player's brain. Neuropsychologia. 2014 Sep;62:152-62. https://doi. org/10.1016/j.neuropsychologia.2014.07.019

4. Dugué B, Leppänen EA, Zhou HP, Gräsbeck R. Preanalytical factors and standardized specimen collection: Influence of psychological Stress. Scand J Clin Lab Invest. 1992 Feb;52(1):43-50. https://doi. org/10.3109/00365519209085439

5. Unterrainer JM, Kaller CP, Halsband U, Rahm B. Planning abilities and chess: a comparison of chess and no-chess players on the Tower of London task. Br J Psychol. 2006 Aug;97(Pt 3):299-311. https://doi. org/10.1348/000712605X71407

6. Atherton, M, Zhuang J, Bart WM, Hu X, He S. A functional MRI study of high-level cognition. I. The game of chess. Brain Res Cogn Brain Res. 2003 Mar;16(1):26-31. https://doi.org/10.1016/s09266410(02)00207-0

7. Nichelli P, Grafman J, Pietrini P, Always D, Carton JC, Miletich R. Brain activity in chess playing. Nature. 1994 May;369(6477):191. https://doi. org/10.1038/369191a0

8. Gobet F, Simon HA. Recall of rapidly presented random chess positions is a function of skill. Psychon Bull Rev. $1996 \mathrm{Jul}$;3(2):159-63. https://doi.org/10.3758/BF03212414

9. Binet A. Mnemonic virtuosity: a study of chess players. Genet Psychol Monogr. 1966 Aug;74(1):127-62.

10. Onofrj M, Curatola L, Valentini G, Antonelli M, Thomas A, Fulgente T. Non-dominant dorsal-prefrontal activation during chess problem solution evidenced by single photon emission computerized tomography (SPECT). Neurosci Lett. 1995 Oct;198(3):169-72. https:// doi.org/10.1016/0304-3940(95)11985-6

11. Gallivan JP, Chapman CS, Wolpert DM, Flanagan JR. Decision-making in sensorimotor control. Nat Rev Neurosci. 2018 Sep;19(9):519-34. https://doi.org/10.1038/s41583-018-0045-9

12. Robbins TW, Anderson EJ, Barker DR, Bradley AC, Fearnyhough C, Henson R, et al. Working memory in chess. Mem Cognit. 1996 Jan;24(1):83-93. https://doi.org/10.3758/bf03197274

13. Gobet F. Expert memory: a comparison of four theories. Cognition. 1998 May:66(2):115-52. https://doi.org/10.1016/s0010-0277(98)00020-1

14. Waters AJ, Gobet F, Leyden G. Visuospatial abilities of chess players. Br J Psychol. 2002 Nov;93(Pt 4):557-65. https://doi. org/10.1348/000712602761381402

15. Grabner RH, Stern E, Neubauer AC. Individual differences in chess expertise: A psychometric investigation. Acta Psychologica. 2007;124(3):398-420. https://doi.org/10.1016/j.actpsy.2006.07.008

16. Kelly EJ. The personality of chess players.J Pers Assess. 1985;49(3):282-4. https://doi.org/10.1207/s15327752jpa4903_13

17. Avni A, Kipper DA, Fox S. Personality and leisure activitiesan illustration with chess players. Personality and Individual Differences. 1987;8(5):715-9. https://doi.org/10.1016/01918869(87)90070-5
18. Nejati M, Nejati V. Frontal lobe function in chess players. Acta Medica Iranica. 2012 Jun;50(3):311-4.

19. Chase WG, Simon HA. Perception in chess. Cogn Psychol. 1973 Jan;4:55-81. https://doi.org/10.1016/0010-0285(73)90004-2

20. Gobet F, Simon HA. Templates in chess memory: a mechanism for recalling several boards. Cogn Psychol. 1996 Aug;31(1):1-40. https:// https://doi.org/10.1006/cogp.1996.0011

21. Lane DM, Chang YA. Chess knowledge predicts chess memory even after controlling for chess experience: Evidence for the role of highlevel processes. Mem Cognit. 2018 Apr;46(3):337-48. https://doi. org/10.3758/s13421-017-0768-2

22. Burgoyne A, Sala G, Gobet F, Mcanamara BN, Campitelli G, Hambrick DZ. The relationship between cognitive ability and chess skill: A comprehensive meta-analysis. Intelligence. 2016 Nov;59:72-83. https://doi.org/10.1016/j.intell.2016.08.002

23. Sala G, Burgoyne AP, Macnamara BN, Hambrick DZ, Campitelli G, Gobet F. Checking the "Academic Selection" argument. Chess players outperform non-chess players in cognitive skills related to intelligence: A meta-analysis. Intelligence. 2017 Mar/Apr;61:130-9. https://doi.org/10.1016/j.intell.2017.01.013

24. Rennig J, Bilalic M, Huberle E, Karnath HO, Himmelbach M. The temporo-parietal junction contributes to global gestalt perceptionevidence from studies in chess experts. Front Hum Neurosci. 2013 Aug;7:513. https://doi.org/10.3389/fnhum.2013.00513

25. Bechara A, Damasio H, Damasio AR. Role of the amygdala in decision-making. Ann NY Acad Sci. 2003 Apr;985:356-69. https://doi. org/10.1111/j.1749-6632.2003.tb07094.x

26. Gläscher J, Adolphs R, Damasio H, Bechara A, Rudrauf D, Calamia M, et al. Lesion mapping of cognitive control and value-based decision making in the prefrontal cortex. Proc Natl Acad Sci USA. 2012 Set;109(36):14681-6. https://doi.org/10.1073/pnas.1206608109

27. Liebherr M, Schiebener J, Averbeck H, Brand M. Decision making under ambiguity and objective risk in higher age - A review on cognitive and emotional contributions. Front. Psychol. 2017 Dec;8:2128. https://doi.org/10.3389/fpsyg.2017.02128

28. Kozlowski D, Hutchinson M, Hurley J, Rowley J, Sutherland J. The role of emotion in clinical decision making: an integrative literature review. BMC Medical Education. 2017 Dec;17:255. https://doi. org/10.1186/s12909-017-1089-7

29. Kotov A. Think like a grandmaster. London: B.T. Batsford Ltd.;1973.

30. Alipour A, Seifzadeh S, Aligholi H, Nami M. QEEG-based neural correlates of decision making in a well-trained eight years-old chess player. J Integr Neurosci. 2017 Oct;25:1-14. https://doi.org/10.3233/ JIN-170056

31. Aciego R, Garcia L, Betancort ME. The benefits of chess for the intellectual and social-emotional enrichment in schoolchildren. Span J Psychol. 2012 Jul;15(2):551-9. https://doi.org/10.5209/rev_ SJOP.2012.v15.n2.38866

32. Demily C, Cavézian C, Desmurget M, Berquand-Merle M, Chambon $\checkmark$, Franck N. The game of chess enhances cognitive abilities in schizophrenia. Schizophr Res. 2009 Jan;107(1):112-3. https://doi. org/10.1016/j.schres.2008.09.024 
33. Jones E. The problem of Paul Morphy.J Psychoanal. 1931 Jan;7:2-23.

34. Sala G, Foley JP, Gobet F. The effects of chess instruction on pupils' cognitive and academic skills: State of the art and theoretical challenges. Front Psychol. 2017 Feb;8:1-4. https://doi.org/10.3389/ fpsyg.2017.00238

35. Sala G, Gobet F. Does chess instruction improve mathematical problem-solving ability? Two experimental studies with an active control group. Learn Behav. 2017 Dec;45(4):414-21. https://doi. org/10.3758/s13420-017-0280-3

36. Troubat N, Fargeas-Gluck MA, Tulppo M, Dugué B. The stress of chess players as a model to study the effects of psychological stimuli on physiological responses: an example of substrate oxidation and heart rate variability in man. Eur J Appl Physiol. 2009 Feb;105(3):343-9. https://doi.org/10.1007/s00421-008-0908-2

37. Divinsky N. The Chess Encyclopedia. New York; Facts on File. 1991. In: https://www.biblio.com/book/chess-encyclopedia-divinskynathan/d/1153377545

38. Sunnucks A. The Encyclopedia of Chess. 2. ed. New York: St Martin Press; 1976

39. Crowther M. "The week in chess". Lembit Oll 1966-1999. London: London Chess Center; 1999.
40. Divinsky N. The Chess Encyclopedia. New York: Facts on File; 1991.

41. Sicilian Defense: Richter-Rauzer Variation, Vitolins Variation (B62). Available from: https://chesstempo.com/gamedb/opening/2242

42. Shenk D. The Immortal Game: a history of chess. 1. ed. New York: Penguin Random House; 2006. p.143.

43. Frank B. Bobby Fischer: profile of a prodigy. rev. ed. New York: McKay; 1973.

44. American Psychiatric Association. Diagnostic and Statistical Manual of Mental Disorders. 5. ed. Washington, DC:APA; 2013.

45. Sánchez MA. Jose Raul Capablanca:A chess biography. Jefferson, North Carolina: Ed. McFarland \& Company; 2015.

46. Du Mont J. Memoir of Capablanca. In: Golombek H. Capablanca's Hundred Best Games of Chess. London: G. Bell \& Sons Limited ; 1959. p.1-18.

47. Hernandez-Meilan O, Hernandez-Meilan M, Machado-Curbelo C. Capablanca's Stroke: An Early Case of Neurogenic Heart Disease. Cuban-World Champion of Chess 1921-1927. J Hist Neurosci. 1998 Aug;7(2):137-40. https://doi.org/10.1076/jhin.7.2.137.1866

48. Cherniaev A. Harry Nelson Pillsbury: A Genius Ahead of His Time. Arkhangelsk, Russia: OM-Media, 2006.

49. Lasker E. Lasker's Chess Magazine.v. 2. New York: Moravian Chess; 1905 